\title{
Discussion on Cost Control of Logistics Enterprises from the Perspective of Logistics Operation Function
}

\author{
Zhirong Shen \\ Jiangsu University of Science and Technology \\ Zhenjiang China
}

\author{
Xiaoli Li \\ Jiangsu University of Science and Technology \\ Zhenjiang China
}

\begin{abstract}
As a new service industry, the logistics industry has developed rapidly in recent years. However, high costs but low profits make logistics enterprises switch, close down or be merged. In order to solve the problem of high costs of logistics enterprises, this article investigates the costs of a logistics enterprise from the perspective of logistics operation function, analyzes reasons of the high costs by using relevant statistical data, combined with the cost control methods, making the best cost control decision-making, the formation of cost-effective to improve the best cost control program, providing a reference for logistics cost control of logistics enterprises.
\end{abstract}

\section{Keywords-logistics enterprise; logistics cost; cost control}

\section{INTRODUCTION}

Going with social transformations and the advancement of technological revolution, more and more attentions have been paid to the modern logistics, which has been become the fifth largest service industry following after traffic, transportation, finance, information and commerce in China. The logistics, a new industry emerging in recent years, has made a rapid progress, data show that the express delivery enterprises in China completed the delivery of 1.2 billion mails and parcels in 2007, which increased 20.7 billion in 2015, and the average annual compound growth rate reached $42.76 \%$. In the first half of 2016, the express delivery completed totaled 13.25 billion, an increase of $56.7 \%$, the business income totaled RMB 171.46 billion, an increase of 43.4\%[1]. Facing such a good development prospect, the status quo of the express delivery industry is the continuous declination of profits. It is estimated that the gross profit per parcel was less than RMB 1 in 2014, and less than RMB 0.5 2015. [2] Due to high costs but low profits, some logistics enterprises even run under deficit, a lot of small and medium-sized logistics enterprises, facing worse environment for survival, start to leave the trade, go into liquidation or are merged.

The Survey on Burdens of Logistics Enterprise and Business Environment in 2015 released by China Federation of Logistics and Purchasing shows, in recent years, labor costs of enterprises have been on up trend year by year, and labor costs of logistics enterprises account for $25 \%$ of the costs of main business, an increase of $2 \%$ than the previous year, and the average prices of lands for logistics enterprise rise generally and warehouse rents also go up sharply. [3] With the continuous increase in hardware costs as storage, rent, facilities and labor and the gradual access of foreign logistics enterprises after the opening-up of the express delivery market in the country, some small and medium enterprises owning lower market share and weak capital strength, under the great shock, are facing risks of being eliminated. Besides, the Medium and Long-term Layout for Logistics Industry (2014-2020) promulgated by the State Council provides clearly that the state will aim to educe logistics costs, enhance the scale and intensive level of logistics enterprises, strengthen the construction of logistics infrastructure network, enhance the logistics socialization and specialization, further strengthen the information-based logistics construction, promote the modernization of logistics technology and equipment, strengthen the standardization of logistics, promote the coordinated development of regional logistics, and actively promote the international logistics, and vigorously develop green logistics, etc. Besides, it has proposed 12 key projects including multimodal transport, logistics park, agricultural logistics, manufacturing logistics and supply chain management, etc. [4]As a result, under the policy of logistics reorganization in the country, a lot of medium and small-sized logistics enterprises, due to higher costs and poor information construction, have been leaving the trade, closed down or merged.

In order to survive the fierce competition and even occupy market shares in the international logistics market instead of being eliminated, it is a must for China's logistics enterprises to improve the efficiency of logistics service, lower logistics costs, increase economic benefits and intensify the competitive advantages of their own. Based on the case of a logistics enterprise where it conducts control on the logistics costs from diverse aspects including warehousing, loading and unloading, packaging, distribution and transportation and so on, the article borrows relevant statistical data to analyze the reasons of high costs of the logistics enterprises A, and adopts the cost control method for the optimal cost control decision-making, and finally proposes the best cost control program to raise the economic benefits. The cost control from diverse aspects of logistics can not only achieve the optimal allocation of resources and optimize the operation, but also build a complete logistics system, which will save the manpower, finance and material resources needed in transportation, storage, loading and loading, packaging and distribution, so that the costs and operation of logistics enterprises are kept in an optimized state. 


\section{THEORIES RELATED TO LOGISTICS COST CONTROL}

\section{A. Introduction to Costs of Logistics Enterprises}

Costs of logistics enterprises mainly refer to the monetary expenditure used for materialized labor and human labor, including the total of manpower, finance and materials consumed in the product-related packaging, transportation, storage, loading and unloading, circulation processing and logistics management as well as the inventory-related capital costs, loss costs of goods, insurance and tax [5]. The essence of cost control is to reduce the logistics expenditure of all aspects with the logistics service level guaranteed.

As per the logistics operation functions, the cost control of logistics enterprises are divided into five parts including warehousing control, loading and unloading control, packaging control, distribution control and transportation control, in order to strengthen the cost control in logistics enterprises and reduce logistics cost, it needs to control the costs in warehousing, loading and unloading, packaging, distribution and transportation "Fig. 1".

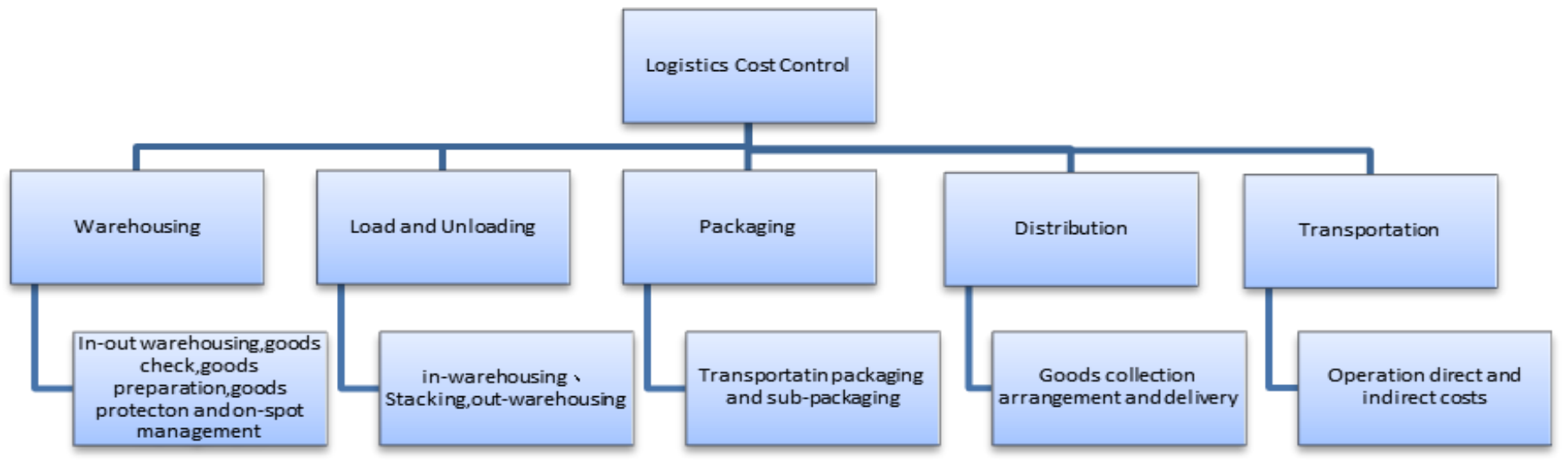

Fig. 1. Logistics cost control

\section{B. Characteristics of Costs}

Products of logistics enterprises are logistics services, compared with tangible products, logistics services have characteristics: intangible, instantaneous and diverse [6]. The characteristics of logistics services determine that the costs of logistics enterprises are also intangible, instantaneous, and diverse. The invisible costs mean that before providing logistics services the logistics enterprises are unable to express the existence of costs through specific products; the instantaneous costs means that when providing logistics services the logistics enterprises have to attribute the costs arising to the costs of current period but not to the next period; the diverse costs mean that due to the difference in goods quantity, storage period, transport distance during the logistics operation, the services that logistics enterprises provide different greatly, making a great difference in the cost for the service.

\section{StATUS QUO OF LOGISTICS ENTERPRISE A In COST CONTROL}

\section{A. Introduction}

Set up in 1995, the logistics company A has undergone the transformation from the railway transport to a third party logistics. Within two decades, the company has been focusing on improving the service quality to continuously meet the market demand and become a leading enterprise in logistics and supply chains in Jiangsu Province. The company is devoted to three service fields namely contractual logistics and value-added service on the basis of logistics bidding and supply chain integration programs; door-to-door express delivery services without blind places in urban areas; warehousing, distribution, finance, trade and information intelligent services on the basis of logistics services.

The company A has more than 1,500 employees, $90 \%$ of whom have college education or above, having rich logistics experience, the departments set up posts and arrange full time workers according to the needs. Main departments include business department, transportation department, finance department, information technology department, personnel department and customer service department. All the departments are in a division, the business department takes charge of various orders; the transportation department takes charge of goods transport to the destination at the request of customers according to orders; the information technology department takes charge of tracking and improving the goods address information of customers and providing correct address; the finance department take charge of collecting goods payment and financial budgets; the personnel and customer service department takes charge of new employee training, attendance registration and performance evaluation; the customer service department takes charge of customers' consultancy and solving complaints. Each department has different business, all run in order, through the clear division and co-operation, the company runs well and the size of the company is expanding gradually. Initially the business of the company A was relatively single, it was mainly engaged in the selftransport, and most transports were completed by vehicles of its own, later it began to adopt the rail-based transport, with the size growing increasingly, it was converted formally into a third-party logistics company, at present, it 
has achieved the jump from traditional logistics to modern one.

\section{B. Status Quo of Cost Control and Problems Existing in the Company A}

TABLE 2 DisTRIBUTION OF LOGISTICS COST OF THE COMPANY A DURING 2011-2015 (UNIT: TEN THOUSANDS YUAN)

\begin{tabular}{|l|c|c|c|c|c|}
\hline \multicolumn{1}{|c|}{ Item } & $\mathbf{2 0 1 1}$ & $\mathbf{2 0 1 2}$ & $\mathbf{2 0 1 3}$ & $\mathbf{2 0 1 4}$ & $\mathbf{2 0 1 5}$ \\
\hline $\begin{array}{l}\text { Warehousing } \\
\text { cost }\end{array}$ & 2126.12 & 2527.44 & 3128.90 & 3730.37 & 4130.69 \\
\hline $\begin{array}{l}\text { Loading and } \\
\text { unloading } \\
\text { cost }\end{array}$ & 623.33 & 689.46 & 708.25 & 725.18 & 788.25 \\
\hline Packing cost & 234.02 & 285.72 & 308.93 & 394.89 & 481.45 \\
\hline $\begin{array}{l}\text { Transport } \\
\text { cost }\end{array}$ & 3017.02 & 3428.43 & 3930.51 & 4031.17 & 5973.29 \\
\hline $\begin{array}{l}\text { Distribution } \\
\text { cost }\end{array}$ & 509.01 & 619.21 & 701.61 & 821.62 & 932.36 \\
\hline $\begin{array}{l}\text { Logistics } \\
\text { information } \\
\text { cost }\end{array}$ & 51.71 & 92.22 & 108.37 & 168.21 & 192.30 \\
\hline $\begin{array}{l}\text { Logistics } \\
\text { management } \\
\text { cost }\end{array}$ & 921.30 & 989.27 & 1156.21 & 1278.92 & 1401.09 \\
\hline Total & 7482.51 & 8631.75 & 10042.78 & 11150.36 & 13899.43 \\
\hline
\end{tabular}

1) Warehousing cost control: The logistics operation needs to go through a number of procedures, in which the warehousing is the most important and also essential, starting with traditional material storage and circulation center to a logistics node, the warehousing has been a core point existing to coordinating the overall logistics operation. Within the logistics system, the warehousing logistics center is an important hub, plays a connecting role between the preceding and the next. The upstream of logistics are factories, the downstream are users. The selection of location for warehousing center means that one or more locations are selected in an economic area with certain supply and demand to set up a distribution center. A wellrun warehousing logistics center may save costs effectively and promote the coordination and distribution of production and consumption in order to ensure the balanced development of logistics systems, besides, it may also provide enterprises with professional, efficient, personalized and perfect value-added logistics services. Seen from Table 2 , the warehousing costs increased continuously during 2011 to 2015 , changing from $28 \%$ of total costs in 2011 to $30 \%$ of total costs in 2015 , which was on the rise, so it is very important to control the costs of warehousing so as to reduce the entire logistics costs. Seen from the proportion of the costs in the logistics, the costs in manpower, inventory damage and so on accounted for $75 \%$, main reasons for which were the unreasonable warehousing locations, the low-level warehousing management resulted high costs in labor and inventory damage. Therefore, to select reasonable warehousing locations and improve the warehousing management level is a key to reduce the warehousing costs and raise he economic benefits. In order to reduce the warehousing costs without affecting the economic benefits of other aspects in the logistics, it is necessary to take a combination of internal factors as business conditions and policies and external factors as traffic conditions nearby and customers' needs and take into all factors account so as to improve the overall logistics efficiency.

2) Loading and unloading cost control: Loading and unloading costs refer to the expenditure used for goods loading and unloading which key parts for aspects in logistics activities, involved in all aspects of the logistics. Seen from Table 2, during 2011 to 2015, the loading and unloading costs accounted for about $6 \%$ of the total, in 2015 the loading and unloading costs had increased from 6.2333 million yuan five years ago to current 7.8825 million yuan. The loading and unloading costs cannot be ignored in the entire logistics cost control, According to the relevant data, the rate of good damage during loading and unloading in the logistics in China reached $1.6 \%$, twice of that in developed countries, the logistics companies have to bear the loss of goods damages, which will increase the loading and unloading costs and affect the corporate images. [7] However the Company A failed to regard quality of workers for loading and unloading, who, due to the low educational background and lack of skills in operation, failed to follow rules as handling with care, resulting in a higher probability of goods damages. In particular, some goods fragile as glass, ceramics and the like are easy to break during the brutal loading or unloading. In addition, due to the lower mechanical operation for loading and unloading in the Company A, it cannot implement the automated loading and unloading and has to rely on manpower for handling goods, resulting in excessive labor consumption, low-efficiency loading and unloading, as well as higher rate of goods damages.

3) Packaging cost: Packaging cost refers to the expenditure used for goods packaging within a certain period by logistics enterprise, which is the end of production process and the starting point of logistics service. The packaging cost comprises material cost, machine and equipment cost, technical costs, manpower costs, auxiliary costs and the like. In 2011, the packaging cost of the Company A accounted for about $3 \%$ of the total and about $4 \%$ in 2015 , the growth rate was not higher, and the growth trend was slow, accounting for a small proportion of the logistics costs, yet the packaging weight and volume will affect the costs of other aspects in the logistics such as transportation costs influenced by packing weight, loading and unloading costs influenced by packing technologies, so the packaging cost control shall be still regarded. "Fig. 2" shows, main costs as labor cost and inventory damage costs accounted for $81 \%$ in the aspect, so the unreasonable packaging will cause a waste of not only packaging materials but also labors, resulting in the increase of packaging costs. Meanwhile, packaging workers have no correct senses of saving, paying little attentions to the lowvalue packaging materials such as a piece of paper or a roll of tape, resulting in logistics packaging beyond the needs, and the over protection of goods in logistics accumulated was also a serious waste. The Company A did not collect the used packaging and other ancillary materials for recycling and had no a concept of saving, resulting in a waste of packaging materials. 


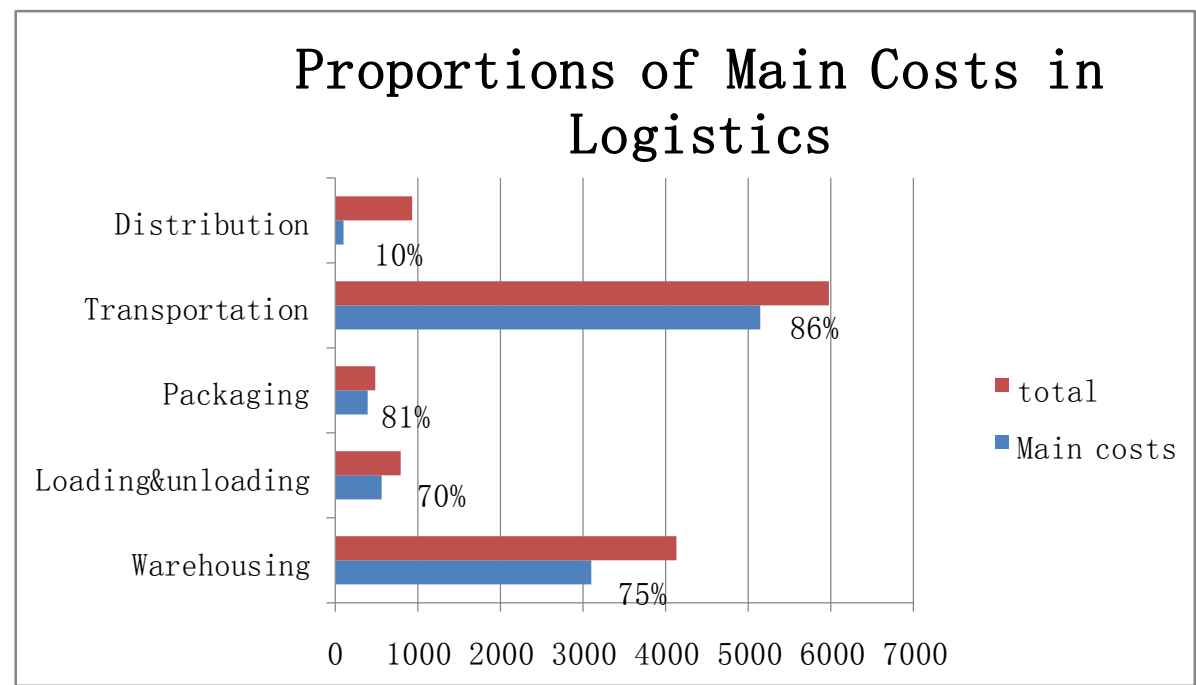

Note: Main costs refer to the costs which are adjustable and controllable in the logistics, such as labor cost, inventory damage costs, tolls, fuel costs, picking-up costs, delivery costs, etc.

Fig. 2. Proportion of main costs for logistics (Unit: ten thousand yuan)

4) Transportation cost: Transportation is the most important part in the logistics and a core function of the logistics system. Transportation cost, as an important part in the logistics costs, refers to an expenditure used for materialized labor and human labor in moving special goods by transport enterprises, namely various fees and expenditures, such as wages, fuel costs, depreciation costs, office expenses, etc. [8]. The purpose of transportation cost control is to minimize the total cost of transportation without affecting the reliability, safety and speed of the transportation. "Fig. 3" shows, the transportation costs of the Company A accounted for $43 \%$ at most of the total cost of logistics, accounting for $33 \%$ in 2014 , increased by $48 \%$ compared with that in previous year, in all logistics costs, it had the fastest growth rate, and in a trend of sustainable growth. Transportation costs of the Company A comprise labor costs, fuel costs, tolls, transport insurance and outsourcing transportation costs. There are also many factors that affect transportation costs such as transportation volume, means of transportation, transport mileage, technical improvement in loading and unloading, and transportation rate. Main reasons for higher costs, improper transportation vehicles and remote transportation of the Company A include: not considering influencing factors, failure in direct transportation, stowage transportation and carrying capacity for transportation, etc. Unreasonable modes of transportation result in a longer transportation distance, lower the transport speed and increase the probability of goods damages, which cause an unnecessary waste of resources and increase the logistics costs, therefore, to reduce the empty load and unreasonable transportation is a primary premise to lower the transportation costs. 


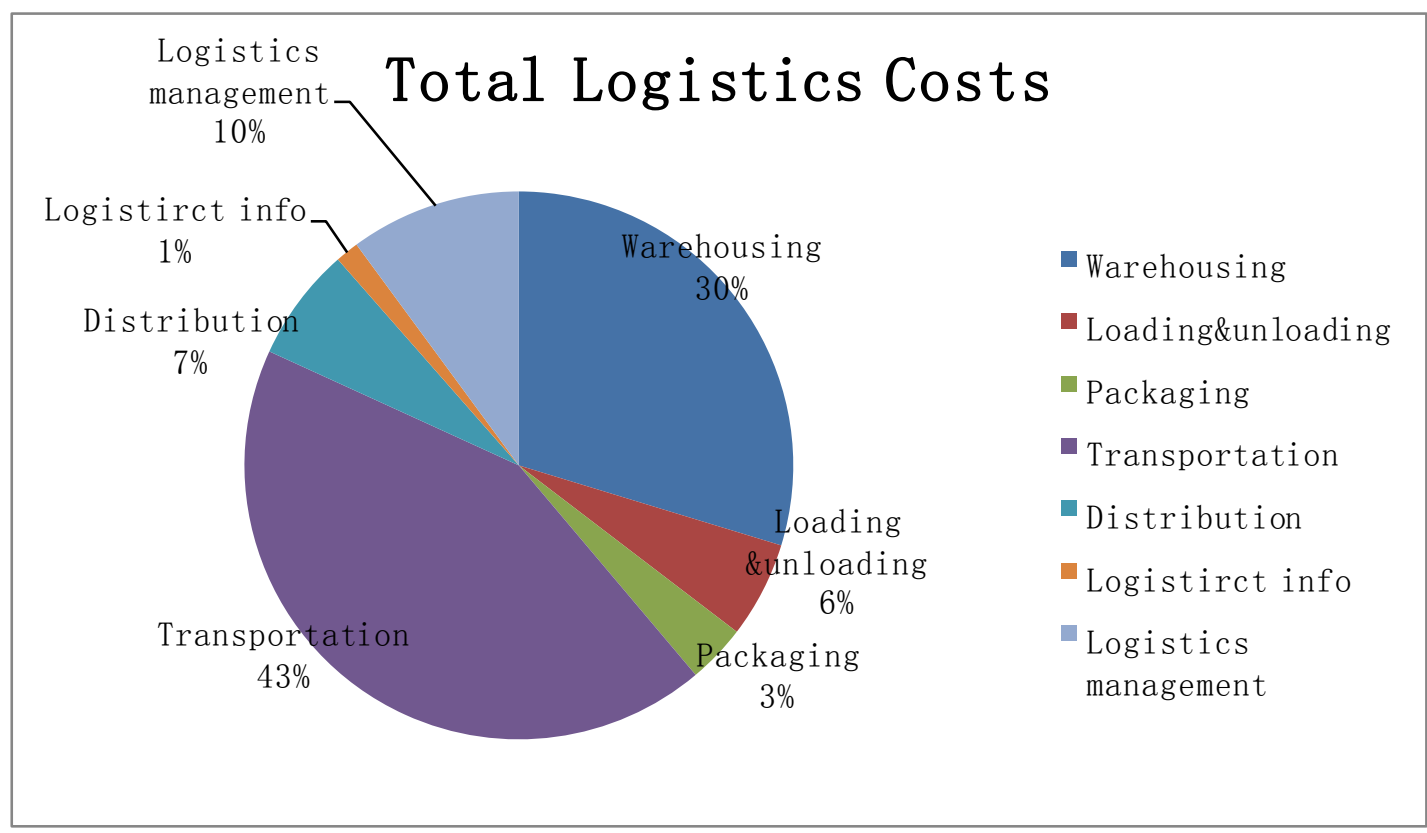

Fig. 3. Cost proportion in the total of the Company A in 2015

5) Distribution cost: Logistics distribution, facing directly customers, is an important part to improve the level of logistics services. Distribution operations include storage, loading and unloading, keeping, sorting, stowage, delivery and so on, and the logistics are finally achieved through the distribution. From 2011 2015, distribution costs of the Company A accounted for about $6 \%-7 \%$ of the total, and labor costs and inventory damage costs accounted for $10 \%$. Main reasons for the higher costs of the Company A are vague distribution process plan, irrational distribution procedures and lower automation in distribution, resulting in low distribution efficiency. During the distribution, temporary distribution, emergent distribution or unplanned distribution at any time will greatly increase the distribution costs, because the distribution makes vehicles be not fully loaded, and it is a waste of mileage. The logistics distribution plan is vague, there are no distribution procedures made in advance, affecting the efficiency of the whole distribution, so it needs to analyze customers' needs and product variety, specification and quantity so as to determine the distribution time and routes and to lower the distribution costs.

\section{Measures To StREngthen Cost CONTROL For LOGISTICS ENTERPRISES (TAKING THE COMPANY A AS AN EXAMPLE)}

\section{A. Measures to Strengthen Warehousing Cost Control}

1) Take into account various factors and rationally select warehousing locations: Factors affecting the selection of warehousing location include: (1) Traffic conditions: transport efficiency is the core for the operation of warehousing center, and the traffics surrounding are the key for transportation. It includes clear ways and road level around the distribution center. (2) Supporting infrastructures: Whether the warehousing center can run well or not has a close relation with the supporting infrastructures at the location. When selecting warehousing locations, it needs to consider supporting infrastructure such as communications, civil work, energy, safety and fire fighting. (3) Economic benefits: Economic benefits is a main factor affecting the selection of warehousing location, as for this factor, three points should be considered: first, the location between customers and ports and the warehousing center, second, the rent level of the warehousing center, third, local human resources and salary level. (4) Policies and laws: the location selected for establishment of the warehousing center is seriously influenced by local laws and polices, mainly including land use planning, taxes and fees and policies.

During the selection of location, diverse factors shall be considered such as customer, natural conditions, social situations as well as the internal factors as business conditions and policies and external factors as traffic around the warehousing and customers' demands. First of all, according to the operation strategy, the Company A should reasonably determine the location of the warehousing, nature and construction patterns; Second, it shall also consider whether it is convenient for loading and unloading of materials, removing barriers for stacking materials so as to make various operational processes well run and improve the overall efficiency. Finally, decision makers must grasp the road and rail planning at the location of the warehousing, based on which, select the nearest location for warehousing , meanwhile, investigate the drainage, power supply and other energy supply at the location, avoiding the difficulty in drainage, power and other so as to ensure the normal operation.

2) Adopt the "first in and first out, quick in and quick out" mode: The "first in and first out" means that according to goods warehousing time, rely on software with time-ordering for an automatic ordering of goods in and goods out. [9] The 
Company A should adopt a computer-aid management system and form a combination of "first in and first out and quick in and quick out", accelerate the turnover and reduce the labor consumption. The most efficient method is to adopt the Drivein Rack System, which can not only improve the use efficiency of the warehousing but also achieve the mechanical and automated warehousing management so as to raise the warehousing management level.

\section{B. Measures to Strengthen Loading and Unloading Cost Control}

1) Improve the quality of loading and unloading workers and eliminate ineffective operations: The Company A should conduct training of professional knowledge on the loading and unloading worker to improve their operational level or engage professionals to do directly, so that it can not only improve the efficiency of loading and unloading operations but also lower the rate of goods damages. In addition, minimize the number of loading and unloading to avoid the operations without logistics effect. Besides, inefficient operation can be lowered through light, simple and practical packaging.

2) Carry out mechanical operation in loading and unloading and promote the a combination of loading and unloading: In order to avoid the adverse effects caused by manpower-based operation in loading and unloading, the mechanical operation for loading and unloading is an important trend. The higher the mechanization of loading and unloading, the higher the efficiency of loading and unloading will be. The Company A should increase the investment to mechanical equipment for loading and unloading machinery and strengthen the mechanical management, so that it can not only free the laborers, but also guarantee the safety of workers and goods when handling dangerous goods.

\section{Measures to Strengthen Packaging Cost Control}

1) Carry out mechanical packaging and lower packaging costs: Compared with manpower-based packaging, mechanical packaging can not only reduce labor costs, but also lower the waste of resources due to the poor quality of laborers, doing good to improve packaging efficiency and lower the packaging costs. For example, in order for the production of corrugated boxes, the Company A has hard paper case assembling machine, packing machine, sealing machine, binding machines, etc., if the machines mentioned above-mentioned are connected to form a fully automated corrugated box production line, it can save about $70 \%$ of the labor force and the production efficiency can be greatly improved.

2) Achieve the standardization of packaging specification: The standardization of packing specifications may ensure the quality of packaging and make external sizes of packaging match with transportation tools and mechanical equipment for loading and unloading so as to reduce the costs of transportation operations and loading and unloading. Besides, the standard packaging also improves the stacking efficiency, reduces the warehousing blocking and saves the storage space and warehousing costs
3) Packaging recovery and use: The Company A can set up departments recover the used packaging and other auxiliary packaging materials through various channels and ways, which will be repaired, cleaned or rebuilt for re-use. The recovery of packaging materials can save to some degree packaging materials, labor, energy, electricity consumption due to packaging.

\section{Measures to Strengthen Transportation Cost Control}

1) Optimize the transport plan and improve transport efficiency: Reasonable transportation routes can effectively improve the transportation efficiency and reduce transportation costs. When designing the transportation plan, the Company A should consider the customer's distribution area as a whole, adopt a mathematical model of logistics management, optimize the transportation routes according to the actual demands and reduce the inefficient transportation and redundant mileages during the transportation so as lower the transportation costs.

In addition, the Company $\mathrm{A}$ can also make use of simulation technology, such as ant colony algorithm, genetic algorithm for simulation of the company's operational flows, during the simulated transportation; it should find unreasonable phenomena and raise measures for improvement The Company A shall also combine the currently advanced technologies and information technology with the transportation network so as to detect whether the road for transport is crowded or in construction or not. During the transportation, if the roads concerned are in poor conditions, the information will be submitted to the transportation headquarters in time, the Company may adjust the transport plans in time to minimize its losses. So it should employ technical talents as soon as possible.

Besides, based on goods features, the Company A shall select correct modes of transportation. For example, the higher-value products should be transported rapidly as air transportation; the low-cost products with a larger number should be transported through waterway or rails.

2) Load rationally and reduce empty load: With the transportation cost given, the transportation cost can be reduced by improving the loading mode, raising the loading level and making full use of the capacity and rated load capacity of the vehicle and finally reducing the total transportation cost. Reasonable loading methods include: (1) LTL goods in a vehicle through traffic (2) car load freight unloaded at two or more stations (3) full truck load (4) lightweight stowage (5) a variety of stacking. Meanwhile, make use of out-of-service vehicles for transportation as much as possible, arrange the goods in advance and reduce no-load.

\section{E. Measures to Strengthen Distribution Cost Control}

1) Improve the distribution efficiency through automation techniques: In order to achieve the automation of distribution operations, the Company A must achieve the automation in storage, keeping, unloading and unloading, preparing goods, sorting, stowage and delivery. The efficiency of storage and delivery can be realized through bar code technology and portable terminals; during the keeping, loading and unloading, 
adopt automation techniques to reduce labor costs and realize the standardized operation; create a digital goods preparation system for preparing goods, based on the customer orders, the information system will send digital command to the sorter so as to prepare goods correctly and quickly as per the quantity and type.

2) Strengthen the distribution as planned and arrange rational stowage for vehicles: The Company A should arrange the distribution areas as per the distribution of customers, and keep the customers in a reasonable distribution area for rapid distribution; and arrange the stowage by sorting according to the classified areas, for example, meat and sea food with higher requirements for fresh shall not be mixed with other goods so as to guarantee the goods quality; distributors shall determine the goods orders for distribution as per the time of customers, rationally arrange vehicles, improve the distribution efficiency and guarantee the arrival of goods in time.

\section{CONCLUSION}

Facing the rapid development of information technology and market economy, it is a must for logistics enterprises to make full use of modern conditions for cost management and control, starting from warehousing, loading and unloading, packaging, transportation and distribution, the logistics enterprises should form a complete logistics system so as to achieve the effective control on the logistics costs.

\section{REFERENCES}

[1] Hot Competition in Logistics Costs, Aiming at Intellectual and Information-Based Development, NetEase Finance, http://money.163.com/16/1013/02/C37MMDBT002580S6.html

[2] Logistics Data The Profit of Express Delivery Industry was Below RMB 1 per Parcel in 2014, China E-Business Research Center, http://b2b.toocle.com/detail--6234505.html

[3] China Federation of Logistics and Purchasing, The Survey on Burdens of Logistics Enterprise and Business Environment in 2015 [N].

[4] The "Medium and Long-term Layout for Logistics Industry (2014-2020) that the State Council promulgates [J]. Shanghai Urban Planning, 2014,05:122.

[5] Ding Jianguo, Discussion on Cost Management and Control of China's Logistics Enterprises [J]. China Township Enterprises Accounting ,2013,07:159-161.

[6] Gao Yanjiao, Study on Cost Control of Logistics Enterprises [D]. Jingdezhen Ceramic Institute, 2014

[7] Guo Kai, Study on Cost Control of Logistics Enterprises, taking logistics enterprise A as an example [J]. Logistics Technology, 2015,18:89-92.

[8] Zhao Gang, Analysis of Logistics Cost and Control [ M] . Sichuan, Sichan People's Publishing House, Jun 2009

[9] Yang Fang, Logistics Cost Control [ M] . Tsinghua, Tsinghua University Press, Mar 2014. 